\title{
Overlooked but not forgotten: India as a center for agricultural domestication
}

\author{
By Dorian Q. Fuller and Charlene \\ Murphy, Institute of Archaeology, \\ University College London
}




\section{Introduction}

When the general public thinks of the origins of agriculture they often think of V.G. Childe's (1923) Neolithic Revolution, the fertile crescent, and the spread from East to West of a few select cereal crops; they don't often think of the subcontinent of India. However, this is about to change. Relatively recent and growing archaeological evidence combined with better botanical documentation of wild crop ancestors in South Asia (comprising primarily the sub-Himalayan countries of Bangladesh, India, Sri Lanka and Pakistan) is transforming our understanding of the origins and spread of agriculture in India and around the world towards a new paradigm of "protraction and entangled processes" towards domestication (see Fuller 2010).

India possesses a unique Neolithic transition that has shaped the cultural and ecological trajectory of the subcontinent. Regions of the world that have long been recognized as independent centers of agricultural origins and early civilization include (1) the wellknown sedentary cereal cultivators of the Levant (Near East), (2) wetland rice cultivators of the Yangtze Basin (China), (3) millet cultivators of the North-East Asian steppe, and (4) early maize cultivators of southern Mexico. The indigenous millet-pulse cultivation and pastoralism in different parts of India have received little attention in the search for the origins and spread of early agriculture.

Indeed, much archaeological research has focused on the Indus Valley civilization (also called Harappan civilization). In contrast, little is known about the Neolithic roots of the subcontinent. We do know that in the early Holocene, South Asia was a subcontinent of hunter-gatherers and by 2000 years ago it was mostly inhabited by farmers, with densely populated river valleys, coastal plains, urban populations, states, and even empires. While some of the crops that supported these early civilizations had been introduced from other centers of origin (the Near East, China, Africa), a large proportion had local origins from wild plants native to the subcontinent. This raises questions as to whether these crops were distributed by indigenous hunter-gatherers or from other crops that had been moved to the subcontinent. This local transition from foraging to farming has left tantalizing traces in the linguistics, archaeological, and specifically, the archaeobotanical record.

\section{Locating Domestication in South Asia}

The bio-geographical evidence for the wild progenitors (ancestors) of a number of plant species, together with their occurrence early in regional Neolithic traditions, argues for their local, independent origins and subsequent domestication in India. The ecological niches of these wild progenitors varied but ranged from the savannahs to the nearby moister deciduous woodlands which include the South Deccan, Gujarat, and the western Himalayan foothills, as well as the Ganges basin (Figure 1). It is posited that perhaps around 3500-3000 BCE the cultivation of indigenous millets and pulses such as Horse gram (Macrotyloma uniflorum), mung bean (Vigna radiate) and urd bean (Vigna mungo), 
began with suggested foci of domestication in Saurashtra during the pre-Harappan Padri/Anarta cultural tradition in Western India (Figure 1, zone 5) and Southern India in the ashmound Neolithic tradition (Figure 1, zone 1) (Fuller 2006, 2011, 2013).

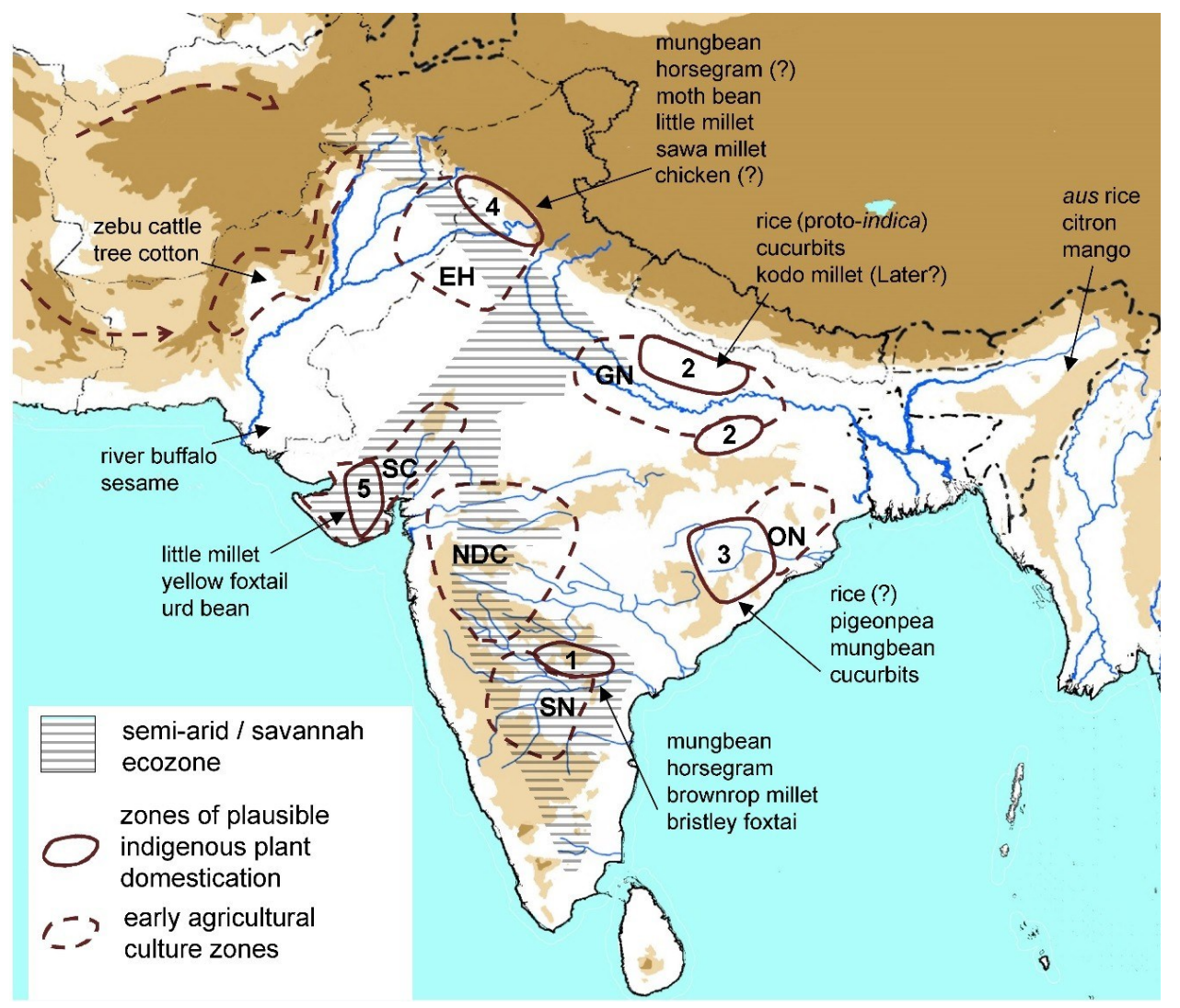

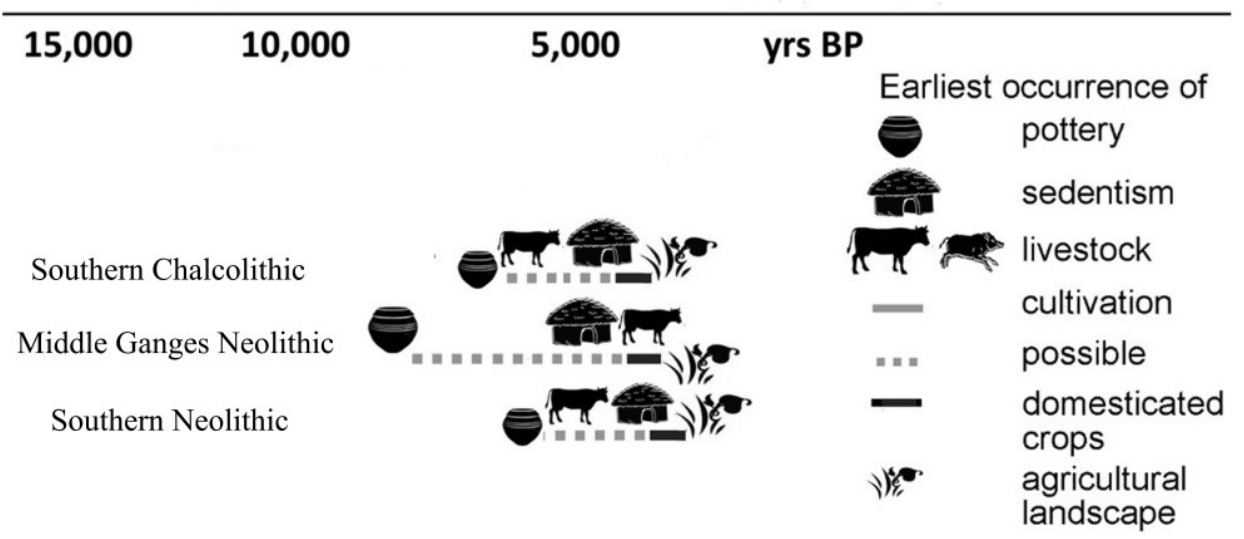

Figure 1: Zones of early farming Neolithic/ Chalcolithic culture areas: (1) Southern Neolithic (2) Middle Ganges and/or Vindhyas Neolithic (3) Orissa Neolithic in the Upper Mahanadi, (4) Eastern Early Harappan in the Foothills of the Indo-Gangetic Divide, (5) Southern Chalcolithic in Saurashtra 
or Southern Aravallis. The semi-arid savannah habitat zone and adjacent woodlands are posited as important areas for most millet and pulse domestications (updated Fuller 2006)

The Ganges plains of northern India have long been discussed as a plausible center for independent plant domestication focused on the Indian subspecies of rice (Figure 1, zone 2) (Sharma et al. 1980; Tewari et al. 2008). It falls within the wild distribution of Asian rice, is watered by perennial rivers and heavy monsoons. By $2000 \mathrm{BC}$ sedentary villages, preserved as mounds, became widespread with an agricultural base of rice, introduced western crops like wheat, barley and lentil, and livestock. These introduced crops and animals (sheep, goat, cattle) spread under the influence of the Indus civilization, but prior to that there was a focus on rice, both gathered and cultivated rice, with some evidence, at least at the site of Lahuradewa (one of the earliest Neolithic sites in India) stretching back to $7000 \mathrm{BC}$. The earliest pottery in India also come from this period and site. Recent insights from rice genetics indicate that fully domesticated rice in India was created through hybridization between introduced varieties of the East Asian subspecies (japonica), domesticated in China, and the unimproved early cultivars native to India (Fuller et al. 2010). It appears that Chinese varieties of rice had been introduced to the Indus region around, and hybridized with, local rice around the time of the end of Harappan civilization (2000-1900 BC). This new improved rice, together with established Indus crops, like wheat and barley, and livestock then provided a productive agricultural package for the transition from low-food production with unimproved rice, together with hunting and fishing that had long sustained Ganges communities, to widespread agriculture, sedentism and demographic increase.

Further East, in the modern state of Odisha, there is the possibility of another trajectory to rice and local domestication (Figure 1, zone 3). Large permanent settlement mounds on the coastal plains were well-established by about 1500 BC. Like the Ganges, modern genetics suggests that fully domesticated and highly productive rice involved the same hybrids that spread through the Ganges after $2000 \mathrm{BC}$, but this region is rich in wild rice populations, as well as the more localized wild ancestor of the pigeon pea, also called Indian red gram, (Cajanus cajan), an important tropical bean. Recent field research has been seeking the origins of the Neolithic here, which was plausibly distinct from the Ganges in its early low-level food production based on local rice and probably tuber crops, but which borrowed improved crops from the Ganges, introduced livestock, and some crops of the South Indian Ashmound traditions (mung bean, horse gram, and millets). This part of eastern India was a frontier interaction between cultural and agricultural traditions, as indicated not just in it crops but also through historical linguistic evidence from peninsular Dravidian languages (primarily South Asian language family), the Munda language family and Indo-European. Ashmounds were a characteristic feature of the Neolithic ashmound tradition. Ashmounds appear in south India circa $3000 \mathrm{BC}$ and are thought to have been formed over a fairly short period of time, perhaps a few human generations, through repetitive, symbolic dung burning events, creating a visible mound in the landscape. These ashmounds, which characterize the Neolithic in southern India, were likely important foci for exchange, cattle trading, communal feasting and social and ritual gatherings, and likely marriage partners (Boivin et al. 2008). 
India is also home to numerous indigenous millets that occur wild in the dry deciduous zones, and the savannah eco-zone. These wild millet grasses would have been available as resources to humans before they were cultivated. Early Harappan assemblages (Figure 1 , zone 4), along with pulses such as horse gram, mung bean and moth bean included little millet, Setaria sp. (genus of foxtail grasses), and Echinochloa colonum (Sawa millet)) (Weber 2003; Weber et al. 2013; Willcox 1992; Bates 2011); the latter was recently identified by the authors from the Harappan site of Tigrana.

In western India, in what is today Gujarat and parts of Rajasthan, evidence for local plant domestication is entwined with the Mesolithic hunter-gatherers traditions of the semideserts around the Thar Desert and the introduction of livestock from the Indus valley west of the Desert (Figure 1, zone 5). While the Gujarat region was incorporated in the expanding influence of the Indus Valley civilization from about $2500 \mathrm{BC}$, evidence for a local transition to food production dates about a millennium earlier (Ajithprasad 2004). Around $3500 \mathrm{BC}$, is the first evidence of pottery alongside evidence for the adoption of sheep, goat and cattle (Patel 2008). Villages emerge with evidence for crops such as urd bean (Vigna mungo) and Indian little millet (Panicum sumatrense). It may be in this broader region where sesame (Sesamum indicum) was first cultivated, which spread as a crop throughout the Indus region and then onto Mesopotamia. The subsistence economies here were ultimately based on adaptions to the tropical savannahs, with importance of pastoralism and drought-tolerant monsoon season cultivation.

This same adaptation is recreated in Southern India savannah corridor based on dispersal of the same livestock species together with local crop domestications (Fuller 2011). The Deccan plateau of South India, a large, arid region featuring rich Neolithic period remains has only recently entered our awareness as a possible center of agricultural origins (Figure 1, zone 1) (Fuller 2002; Fuller et al. 2004, 2007). The staple crops of the Neolithic in this region are such native domesticates as horse gram, mung bean, and browntop millet (Fuller 2011; Fuller et al. 2014). Archaeobotanical evidence from sites from the Southern Neolithic would appear to support the idea of a 'basic Neolithic package' based upon the consistent recovery of mung bean, horse gram and two millets, browntop millet and bristley foxtail millet (Fuller et al. 2001). The early millets of South India were Brachiaria ramosa (browntop millet), which appears to have been overlooked in early archaeobotanical research and now is thought to have been widespread in Indian prehistory, and bristley foxtail millet (Setaria verticillata) (Fuller 2006, 18). 2

Thus, in the south, these wild progenitors of Indian crop domestication span both the tropical wet to the dry deciduous forests on the hills of the Deccan margins and the drier savannah woodland zones of the central peninsula (Fuller et al. 2004, 123-126; Fuller 2011). A scenario may be imaged in which early mobile collectors were combining plant cultivars from across the adjacent habitats in which they frequented in their seasonal hunting and collecting strategy. These native species do not form extensive stands like wild wheats, barley, or wild rice; rather they are often found in local dense patches in favorable microenvironments, such as springs and at the base of slopes for millets and less disturbed scrub patches for the wild horse gram. These wild progenitors would have 
slowly become incorporated into foraging practices when spatially and seasonally available within the environment. Over time, the collectors/foragers exploiting these plant species would have likely sought to advantageously concentrate them together in a constructed niche, perhaps in the transitional zone of wet to dry deciduous forest and expand these stands through the clearance of other plants along with other beneficial activities (Fuller 2011, S248).

\section{Conclusions}

India had a varied Neolithic transition from foraging to farming in different parts of the subcontinent with domestication and diffusion of different crop species. As a case study for the transition to agriculture it has much to offer archaeologists and environmental scientists alike for our understanding of this process. Although inspiration through information exchange from distant farmers from the Near East, China and Africa cannot be excluded, it is clear that local agricultural origins were based on the cultivation and domestication of plants chosen from local wild populations. We now think that it is likely that local domestication events in India were occurring alongside agricultural dispersals from other parts of the world in an interconnected mosaic of cultivation, pastoralism, and sedentism (Fuller 2006, 2011). As humans in South Asia increasingly relied on a narrower range of plant species, they became entangled in an increasingly precarious and fixed trajectory that allowed them greater subsistence levels to sustain larger populations and their cultural and food traditions (Fuller et al. 2014). Thus, it is perhaps time we changed our perspective on centers of agricultural origins as naturally occurring confluence of favorable environmental conditions to human manipulated and constructed niche environments, which have allowed for multiple plant species in multiple regions around the world to enter into a protracted domestication trajectory.

\section{Acknowledgements}

Current research into comparing pathways towards agriculture including Indian is funded by a European Research Council advanced grants (ComPAg no.323842), from 20132018. 


\section{References Cited}

Ajithprasad, P. (2004).Holocene adaptations of the Mesolithic and Chalcolithic settlements in north Gujarat. In Y. Yasuda \& V. S. Shinde (Eds.), Monsoon and civilization (pp. 115-132). New Delhi: Roli Books.

Bates, J.

2011 The Archaeobotany of Rural Indus Sites: exploring regionality and social change through macrobotanical and phytolith analysis. Unpublished MA thesis. London: University College London, Institute of Archaeology.

Boivin, Nicole, Dorian Fuller Q., Ravi Korisettar, and Michael Petraglia 2008 "First Farmers in South India: The Role of Internal Processes and External Influences in the Emergence and Transformation of South India's Earliest Settled Societies" Pragdhara 18: 179-99.

Fuller, Dorian Q.

2013 "South Asia: Archaeology." In The Encyclopaedia of Global Human Migration, 1:1-9. Chapter 31. Oxford: Blackwell Publishing Ltd, 2013.

Fuller, Dorian Q.

2011 "Finding Plant Domestication in the Indian Subcontinent." Current Anthropology 52, no. Supplement 4 (2011): S347-S362.

Fuller, Dorian Q.

2010 "An Emerging Paradigm Shift in the Origins of Agriculture". General Anthropology 17 , no. $2,1-12$.

Fuller, D.Q.

2007 Non-human genetics, agricultural origins and historical linguistics in South Asia. In The Evolution and History of Human Populations in South Asia, Inter-disciplinary Studies in Archaeology, Biological Anthropology, Linguistics and Genetics. The Netherlands: Springer, pp. 393-446.

Fuller, D.Q.

2006. "Agricultural Origins and Frontiers in South Asia: A Working Synthesis." Journal of World Prehistory 20 (2006): 1-86.

Fuller, D.Q. 2002 Fifty Years of Archaeobotanical Studies in India: Laying a Solid Foundation. In Indian Archaeology in Retrospect. Archaeology and Interactive Disciplines. New Delhi: Manohar, pp. 247-364.

Fuller, Dorian Q., Tim Denham, Manuel Arroyo-Kalin, Leilani Lucas, Chris J. Stevens, Ling Qin, Robin Allaby, and Michael D. Purugganan. 
2014 "Convergent Evolution and Parallelism in Plant Domestication Revealed by an Expanding Archaeological Record." Proceedings of the National Association of Sciences 111, no. 17: 6147-52.

Fuller, Dorian Q, Yo-Ichiro Sato, Cristina Castillo, Ling Qin, Alison R. Weisskopf, Eleanor J. Kingwell-Banham, Jixiang Song, Sung-Mo Ahn and Jacob van Etten 2010. Consilience of genetics and archaeobotany in the entangled history of rice (2010). Archaeological and Anthropological Sciences 2 (2): 115-131

Fuller, Dorian Q., and Emma L. Harvey. 2006 "The Archaeobotany of Indian Pulses: Identification, Processing and Evidence for Cultivation.” Environmental Archaeology 11, no. 2: 219-46.

Fuller, Dorian Q., Ravi Korisettar, and P.C. Venkatasubbaiah. 2001. "Southern Neolithic Cultivation Systems: A Reconstruction Based on Archaeobotanical Evidence.”South Asian Studies 17: 171-87.

Patel, A. K. 2008. New radiocarbon determinations from Loteshwar and their implications for understanding Holocene settlement and subsistence in North Gujarat and adjoining

Sharma, G. R., Misra, V. D., Mandal, D., Misra, B. B., \& Pal, J. N. (1980). Beginnings of Agriculture (Epi-Palaeolithic to Neolithic: Excavations at Chopani-Mando, Mahadaha, and Mahagara). Allahabad: Abinash Prakashan.

Tewari, R., R. K. Srivastava, K.S. Saraswat, I.B. Singh, and K.K. Singh. "Early Farming at Lahuradewa." Pragdhara 18 (2008): 347-73.

Weber, Steve.

2003 "Archaeobotany at Harappa: Indications for Change." In Indus Ethnobiology: New Perspectives from the Field, 175-98. Maryland: Lexington Books.

Weber, Steve, and Arunima Kashyap.

2013 The Vanishing Millets of the Indus Civilization." Archaeological and Anthropological Sciences, May 2013.

Wilcox, G.

1992. Some differences between crops of Near Eastern origin and those from the tropics. In South Asian Archaeology 1989. Monographs in World Archaeology. Madison:

Prehistory Press, pp. 291-299. 